\title{
ANALYSING LESSON-BASED INTERVIEWS USING THE LESSON ACTIVITIES MAP (LAMAP) AS A VISUAL TOOL
}

\author{
Annamaria Savona \\ Department of Arts Education, Schwyz University for Teacher Education \& University of Zurich \\ (Switzerland)
}

\begin{abstract}
During training as generalists, some teachers find it complex and challenging to teach songs and lead class singing. The Song Leading research project longitudinally examines case studies of 16 trainees to explore how they acquire and develop the knowledge and skills to conduct a class singing lesson. The data corpus consists of video-recorded lessons, audio-recorded lesson-based interviews and personalised open-ended questionnaires. In this paper some phases of the interview analysis are presented. As each interview is conducted while watching the video-recorded lesson, its analysis should not be separated from the lesson content. The central question guiding this analysis is: How can the analysis of a lesson-based interview be combined with the video analysis of the lesson itself? We present a visual system to combine the analysis of interviews and videos. This system involves the use of the Lesson Activities Map (LAMap) - the transcript of the class singing lesson - based on the methodology developed in the Song Leading project. During the thematic analysis of the interviews, the LAMap is a visual tool that allows the researchers to systematically describe the lesson moments that were the starting points of the teachers' reflections. In addition, LAMap is a visual tool for collecting initial codes and identifying relationships between potential interview themes. The implications of the use of a visualisation system for lesson-based interview analysis are an added value for the coherence of case study interpretation. The paper contributes to research in education by providing concrete examples of how to make a qualitative analysis process explicit.
\end{abstract}

Keywords: Lesson activities map, reflexive thematic analysis, professional development, song teaching, song leading.

\section{Introduction}

This paper presents some stages of the case study analysis of the Song Leading research project. The project focuses on the cultural practice of group singing in the school context. In many pre-schools and primary schools, the teaching of songs and the conducting of class singing are delivered by generalist teachers (de Vries, 2015). They are expected to achieve and/or consolidate subject-specific skills during their training (Russell-Bowie, 2009). The study aims to explore how pre-service generalist teachers carry out the task of song teaching and reflect on their song leading experiences at three different points during their professional training - initial, intermediate and final. We want to analyse how teachers experience their development, both from a personal perspective and from that of familiarisation and deepening of subject-specific knowledge and skills. The data corpus of the project consists of videos, interviews, and personalised open-ended questionnaires. In this paper some phases of the interview analysis are presented. The examples and discussion concern how the Lesson Activities Map (LAMap) (Savona et al., 2021) - i.e., the transcript of a song leading lesson created with the methodology developed in the Song Leading project - can be a tool for researchers to analyse the lesson-based interviews. The LAMap methodology contributes to qualitative research in education by providing a visual analytical tool. It enhances the characteristics of the subject matter, facilitates the systematic organisation of data, and supports the coherence of the interpretation of verbal data relating to a specific educational event and context.

\section{Design}

The Song Leading research project examines case studies of 16 pre-service teachers attending their three-year training course as generalists. The data set for each case study consists of three video-recorded lessons, three interviews - lesson-based and audio-recorded - and a personalised 
open-ended questionnaire. This data was collected once a year during the pre-service teachers' internships. Five $\mathrm{PhD}$ students and two supervisors work on the ongoing project (2018-2022). Each PhD student has a background as a professional musician and singing or instrument teacher, and/or as a music educator at primary, secondary or tertiary level. The two supervisors are professors with research backgrounds in developmental and cultural psychology, arts education, and research methodology. This information is necessary for positioning the team members in the data analysis process.

\section{Objectives}

This paper aims to show how we use LAMap while analysing interviews. For the analysis of the interviews, we follow the reflexive thematic analysis as defined by Braun and Clarke (2006). They outline six phases for this process. For phases 2, 3 and 4 - generating initial codes (2), searching for themes (3) and reviewing themes (4) - Braun and Clarke (2006) suggest the creation of tables and mind-maps. This suggestion coincides with the LAMap as our visualisation system of a song leading lesson. Through examples, this paper demonstrates how LAMap is a useful visual tool for analysing lesson-based interviews.

\section{Method}

Videos, interviews and personalised questionnaires are analysed with different qualitative methods and methodologies. The interviews, on which we focus in this paper, are analysed through reflexive thematic analysis (Braun \& Clarke, 2006) to identify and describe patterns in the way teachers relate their teaching experience with comments. The analysis is framed within the epistemological approach characterised as the teacher-object-learner paradigm called "didactics" (Reusser, 2008; Schneuwly, 2021). The identification of themes is guided by a semantic and explicit interpretation level based on the relationship between experience, meaning, and language (Wooffitt \& Holt, 2011). Through reflexive thematic analysis we aim to report a detailed and subject-related description of each interview. In the project, each $\mathrm{PhD}$ student is responsible for transcribing video and interview data and guiding the analysis of several case studies. AS, the author of this paper, leads the analysis of Ruth's case, which serves here as an example to show the application of reflexive thematic analysis to lesson-based interviews. Each team member is familiar with the interviews from all the case studies. The analysis of each case is regularly discussed by the team at all stages. As each interview is conducted by watching the video-recorded lesson, the pre-service teacher's comments and reflections are often "triggered" by the context of the lesson in question. In the following paragraphs we provide examples of how the LAMap is used to produce the map of initial codes and potential themes generated by the interview interpretation. Indeed, 'the most basic segment, or element, of the raw data or information that can be assessed in a meaningful way regarding the phenomenon' (Boyatzis, 1998: 63) is often the lesson activity which can be visualised with the LAMap.

\subsection{The LAMap as a visual domain summary}

The LAMap was devised in the initial stage of the Song Leading project in an iterative manner in order to gain a systematic overview of the relevant and recurring activities of each lesson. The result is a methodology for transcribing class singing lessons. It consists of symbols and icons that are used to represent the course of recurrent activities that constitute lessons in this specific subject, such as making semantic gestures to learn the lyrics of the song. Although the analysis of the videos is guided by the same epistemological decisions as the analysis of the interviews, i.e., teacher-object-learner interaction (Schneuwly, 2021), the result of the video analysis is a domain summary (Braun \& Clarke, 2019) and not themes generated by a reflexive thematic analysis. However, the combination of the two analyses contributes to an overview of how the content of the interviews refer to the actions during the lessons. Thus, the pre-service teachers' comments can be directly linked to the course of actions during the lesson as visualised by the LAMap.

Figure 1 shows on the left side the LAMap of Ruth's first leading a class singing lesson. The LAMap is divided into two parts by the speaking line, along which the spoken communication between teacher and children is marked. Ruth's actions are written above the speaking line and the children's below. On the right, the Song Leading Activities Key provides definitions for the symbols and icons that represent the song leading activities in LAMap.

\subsection{The LAMap as a tool for reflexive thematic analysis in education}

The following figures were created for analysing Ruth's first leading of a class singing lesson. Note that they do not show the final results of the analysis, but rather represent the phases 2, 3 and 4 as outlined by Braun and Clarke (2006). Thereby, the LAMap serves as a graphical tool for: 
1) Systematically locating the initial codes of the interview sections during the course of the lesson (phase 2, figure $2 \mathrm{~A}$ ).

2) Contextualising interview extracts concerning the same code to check their coherence before 'nominating' them for potential themes (phase 3, figure $2 \mathrm{~B}$ ).

3) Creating a mind-map of the initial themes generated by the analysis (phase 4, figure 3 ).

Figure 2 (A) shows the LAMap of Ruth's lesson. The vertical lines on the LAMap indicate the moments when Ruth paused the recording to comment. The interview started with an opening dialogue (OD), the video-viewing sections are numbered consecutively (in the figure: 1, 2 and 3), and a concluding dialogue $(\mathrm{CD})$ took place at the end of the video-viewing. The lower part shows the summary table of the initial codes. The code 'known song vs. new song' is highlighted in grey and is selected for the next analysis phase. Figure 2 (B) shows the extracts related to the 'known song vs. new song' code. It provides information about the team member responsible for transcription and translation, the interview section (OD, 1, 2, 3, CD) and the location of the extracts in the transcript (text chunks). Screening the extracts for a single theme is a necessary step to check the coherence of the coding and to nominate initial codes for potential themes.

Figure 3 shows the initial thematic map of the lesson-based interview combined with the LAMap. The symbols and icons highlighted in grey indicate the lesson moments on which Ruth commented while watching the video. From these extracts initial themes and sub-themes were generated, the interpretation of which requires completion through the description of those lesson moments. Other initial themes have been generated from reflections of a general nature and not strictly related to the lesson activities.

\section{Discussion}

The development of visual tools like the ones presented in this article is desirable when analysing interviews based on a context "bound" to a specific event. In the case of the Song Leading project this is the lesson-based interview. Consequently, part of the interview content is derived from the input the interviewer receives while watching the video-recorded lesson. During the analysis of the interviews, the LAMap is a tool for the researchers to systematically locate and describe the lesson moments that gave rise to the teacher's comments. By taking into account the teaching content enacted during the lesson and graphically transcribed in the LAMap, we achieve a convincing coherence between the observed actions and generated themes. However, this essential aspect of analysis remains still a challenge. The transition from description to abstraction of themes with shared meanings requires both familiarity and a distancing from the lesson content (not the interviews!). Researchers have to go beyond description and produce themes with generalised meanings in order to reconstruct and understand how teachers develop skills and how they conceive of their own professional development.

\section{Conclusion}

The aim of this paper was to show how the transcription of a lesson can support lesson-based interview analysis. One example is the use of the LAMap - the transcription of a class singing lesson with the methodology developed in the Song Leading project. The visualisation of the transcribed lesson combined with the interview analysis can offer new possibilities for qualitative research into subject-specific teaching. Comprehensive analytical narratives can be created through both the systematic description of teachers' subject-related actions and the coherent interpretation of their personal perspectives of their own professional development. 
Figure 1. LAMap of the first song leading lesson of the pre-service teacher Ruth.
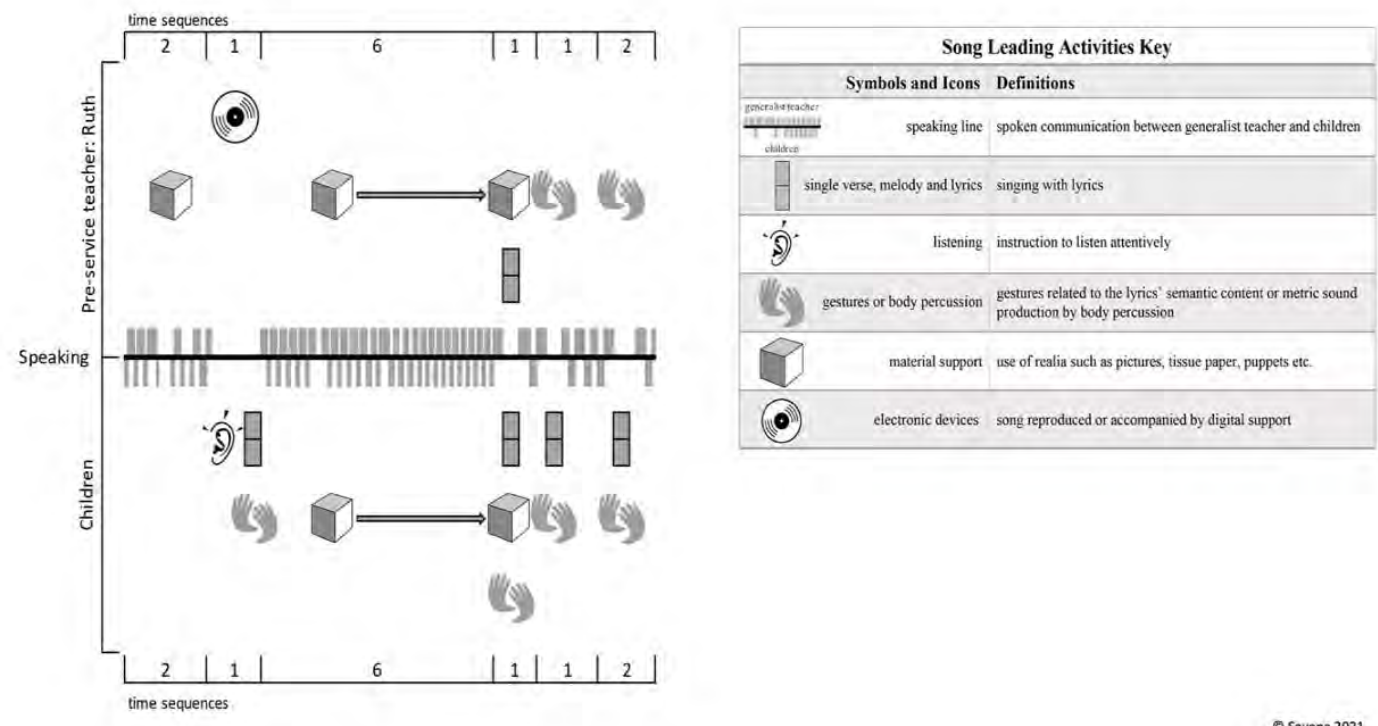

OSavona 2021

Figure 2. LAMap and map of initial interview codes (A). AMap and data extracts coded for 'known song vs. new song' $^{\prime}(B)$.

A
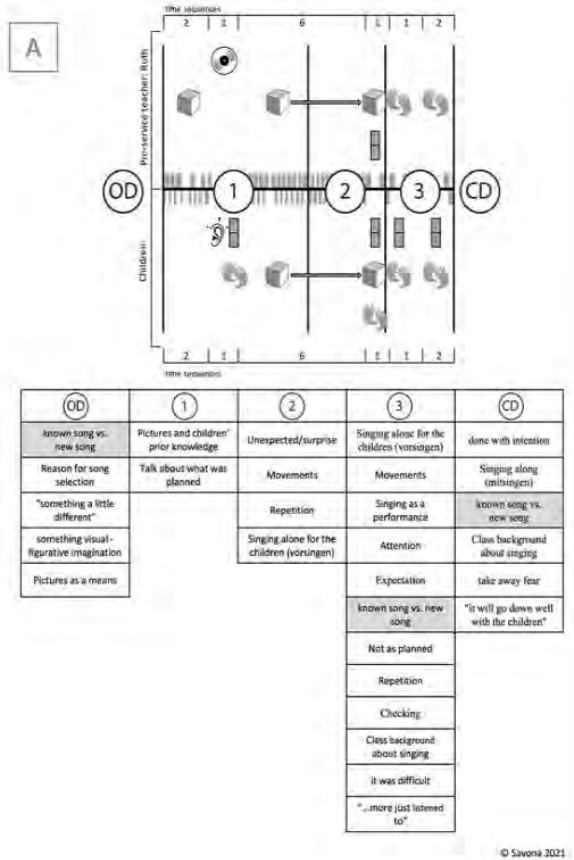

B

(0D)
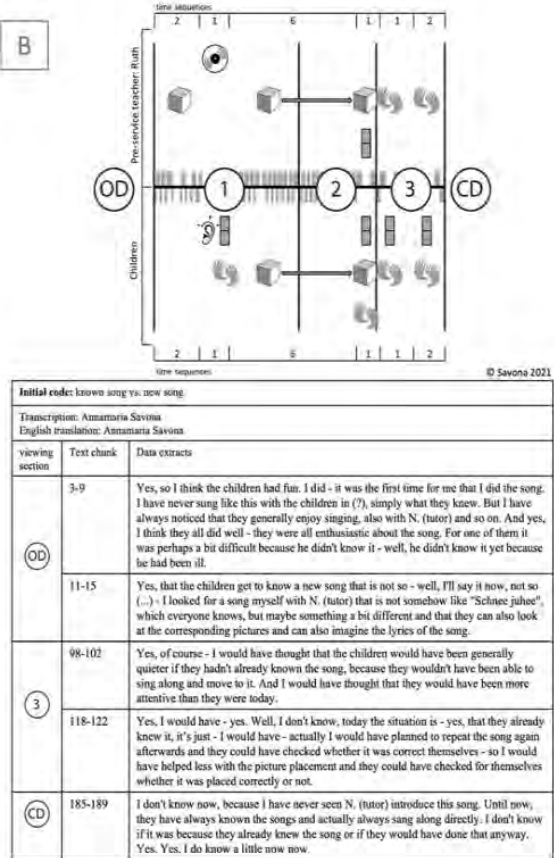
Figure 3. Initial thematic map of Ruth's first lesson using LAMap.

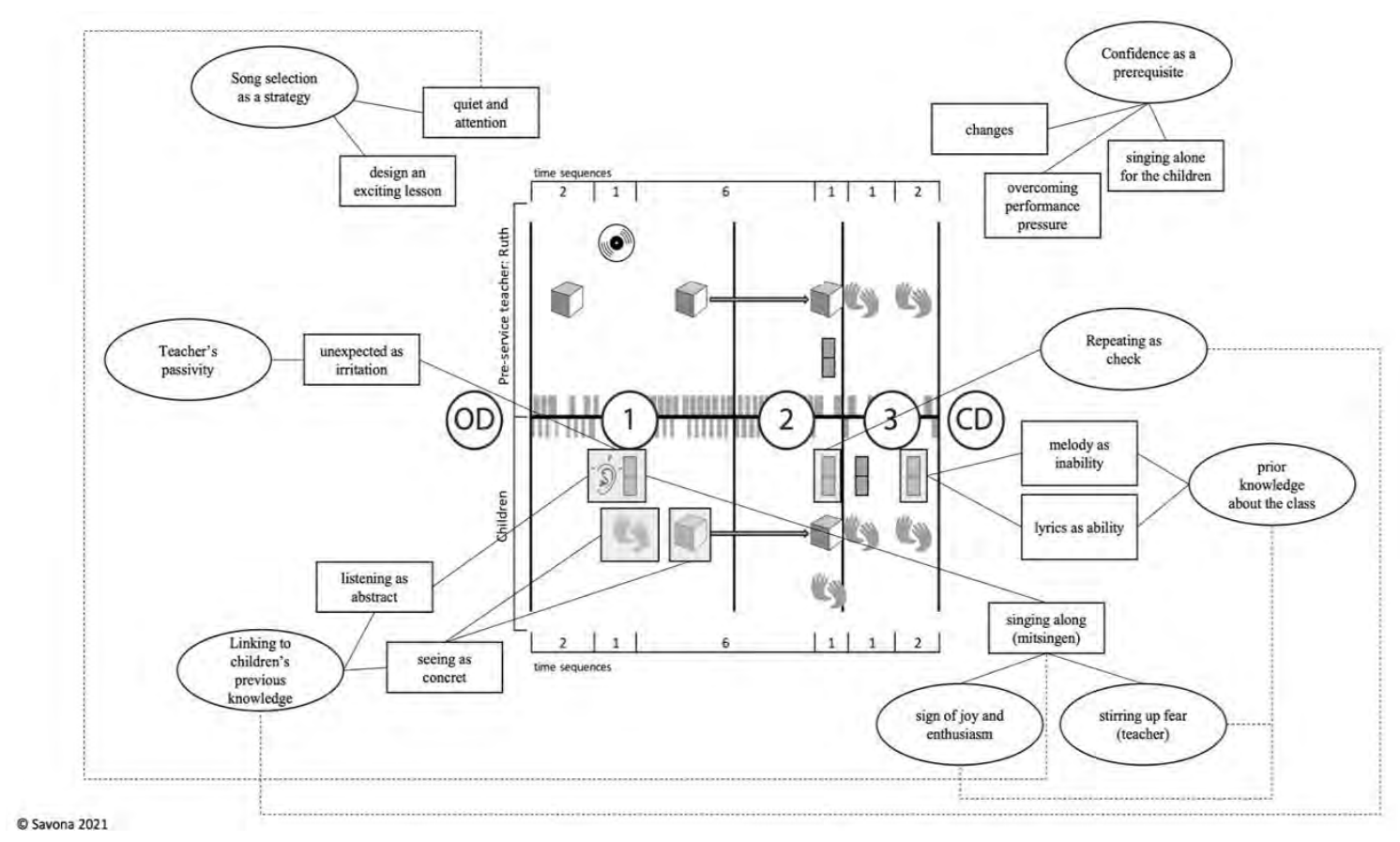

\section{References}

Boyatzis, R.E. (1998). Transforming Qualitative Information. Thematic Anaylsis and Code Development. London: Sage.

Braun, V., \& Clarke, V. (2006). Using thematic analysis in psychology. Qualitative Research in Psychology, 3, 77-101.

Braun, V., \& Clarke, V. (2019). Reflecting on reflexive thematic analysis. Qualitative Research in Sport, Exercise and Health, 1(4), 589-597.

De Vries, P. A. (2015). Music without a music specialist: A primary school story. International Journal of Music Education, 33(2), 210-211.

Reusser, K. (2008). Empirisch fundierte Didaktik - didaktisch fundierte Unterrichtsforschung. Eine Perspektive zur Neuorientierung der Allgemeinen Didaktik. In M.A. Meyer, M. Prenzel \& S. Hellekamps (Eds.), Perspektiven der Didaktik. Zeitschrift für Erziehungswissenschaft. Sonderheft 9 (219-237). Wiesbaden: VS Verlag für Sozialwissenschaften.

Russel-Bowie, D. (2009). What me? Teach music to my primary class? Challenges to teaching music in primary schools in five countries. Music Education Research, 11(1), 23-26.

Savona, A., Stadler Elmer, S., Hürlimann, A.E., Joliat, F., \& Cavasino, G. (2021). The Lesson Activities Map: A domain-specific lesson transcription methodology. European Journal of Educational Research, 10(2), 705-717.

Schneuwly, B. (2021). 'Didactiques' is not (entirely) 'Didaktik'. The origin and atmosphere of a recent academic field. In E. Krogh, A. Qvortrup \& S. T. Graf(Eds.), Didaktik and Curriculum in Ongoing Dialogue (164-184). London: Routledge.

Wooffitt, R., \& Holt, N. (2011). Looking In and Speaking Out: Introspection, Consciousness, Communication. United Kingdom: Imprint Academic. 